\title{
Listeria, haurdunaldirako desafioa?
}

\author{
Listeria, a challenge for pregnancy? \\ Maialen Olazabal Loyola,Nerea Marin Lacarta, Arantza Lekuona Artola \\ Obstetrizia eta Ginekologiako Zerbitzua. OSI Donostialdea. \\ maialen.olazabal@gmail.com
}

\section{Laburpena}

Azken urteotan, Gipuzkoan, listeriosiaren intzidentziaren igoera esanguratsua atzeman da. Arriskutaldeen artean, haurdun dauden emakumeak aurkitzen dira. Transmisio-bide ohikoena helduetan, kutsatutako elikagaien bidezkoa da, eta fetuaren eta jaioberrien kasuan, berriz, transmisio bertikala (plazenta edo erditze-kanalean zehar). Kasuen erregistroa Ingurumen Ikerkuntza eta Osasun Publikoko teknikariek egin dute eta laginen azterketa molekularra Donostia Ospitaleko Mikrobiologia Zerbitzuan eta Mikrobiologia Zentro Nazionalean egin dira, PFGE teknika erabiliz andui ezberdinakisolatzeko. Aldi berean, Gipuzkoan izandako azken urteotako listeriosi kasuen bilaketa klinikoa eginez, zehaztu ahal izan da zein izan den haurdun eta jaioberrien kasuen ezaugarri eta bilakaera. 2008-2014 urte bitartean, Gipuzkoan 73 kasu berri jakinarazi ziren, eta horietatik 52, 20122014 urte bitartean. Urte horietako kasuen informazio kliniko eta mikrobiologikoak aztertu dira lan honetan. 2013. urtean, 22 kasurekin, azken 10 urteetako intzidentzia hirukoiztu zen. Urte horretan, haurdun eta jaioberriak arrisku-taldeen \% 50 izan ziren (9 kasu).Haurdunaren infekzioa detektatzea zaila izan liteke, sintoma inespezifikoak eragiten ditu-eta (digestio-aparatuarekin lotutako sintomak eta sukarra), baina umekiarengan ondorio kaltegarriak izan ditzake (abortu septikoa, goiztiartasuna). Lan honetan aztertutako kasu gehienetan haurdunak sukarrarekin agertu ziren eta kasu gehienetan erditze goiztiarra gertatu zen. Kasuen banaketa eta ezaugarriak ezberdinak izan dira urte batetik bestera. 2012ko kasuek banaketa topografiko zehatz bat izan zuten eta 2014ko kasuak, ordea, elikagai konkretu bati loturikoak izan dira. Lortutako datuen arabera, eta behaketa horren ostean infekzio-bide nagusia elikagai kutsatuen bidezkoa dela ohartuta, prebentzio-neurriak areagotu behar direla atzeman dugu, eta, horretarako, elikagaien inguruko heziketa egokia eta lehen mailako prebentzio-neurriak azaltzen ditugu.

Hitz gakoak: listeria, haurdunaldia, prebentzioa

\section{Abstract}

Listeriosis is uncommon in the general population, but it is far more frequent in pregnant women and newborns. In recent years, we have detected a significant increase in the number of cases in Gipuzkoa. In adults, the source of infection is ingested food and across the placenta to the fetus and newborn (vertical transmission). In this work, we describe the clinical and epidemiological characteristics of listeriosis cases in pregnant women and newborns in Gipuzkoa over a seven year period (2008-2014). Cases were documented by Environmental Public Service technicians and molecular analysis of samples was performed by the Microbiology Service at the DonostiaUniversitary Hospital, in order to identify different bacterial strains. They were 73 new cases of listeriosis between 2008 and 2014, with 52 of them occurring in 2012-2014. We analyzed the microbiological and clinical characteristics of these cases. We also found a 3-fold increment in the incidence of listeriosis during 2013 comparing to 10 years before (22 cases), with 9 cases in pregnant women and newborns. As this disease has no specific clinical manifestations in the mother or newborn (fever and digestive symptoms), diagnosis could be difficult if clinicians are not aware of this possibility. An early diagnosis and treatment (ampicillin) can prevent complications such as premature birth and septic abortion. In the studied population, most of the pregnant women 
presented fever and premature labor. In the light of our data and the finding that infected food is the main transmission route, we consider that more education regarding nutritional health can prevent the majority of cases.

Key words: listeriosis, pregnancy, prevention

Bidalia: 2017ko martxoaren 28ean.

Onartua: 2017ko maiatzaren 2an.

http://doi.org/10.26876/osagaiz.1.2017.79

\section{Sarrera eta helburuak}

Biztanleria orokorrean Listeria monocytogenesbakterioen gorotz-eramaile asintomatikoak \% 10 dira. Batez besteko intzidentzia 0.65 kasu 100.000 biztanle/urtekoa da, Gipuzkoan 2011. urte arte intzidentzia-tasa 9 kasu/urtekoa izan delarik. Azken urteotan, intzidentziaren igoera esanguratsua atzeman da.

Adineko jendeak, haurdunak, jaioberriak, gaixo kronikoak eta erreserba immunologiko baxuko gaixoak arriskuko taldetzat hartzen dira $(1,2)$. Transmisio-bide ohikoena helduetan, kutsatutako elikagaien bidezkoa da; fetuaren eta jaioberrien kasuan, berriz, transmisioa bertikala da (plazenta edo erditze-kanalean zehar) (3).

Lan honen helburua zera da: Gipuzkoan haurdunen artean agertutako listeriosi kasuen ezaugarri epidemiologikoak zehaztea eta jarraibide terapeutikoak zeintzuk izan behar diren adieraztea. Aldi berean, gure zerbitzuan arrisku-taldeak daudela kontuan izanik, haurdunak eta fetuak zein jaioberriak, diagnostiko goiztiar bat egiteko protokolo bat eraiki da. Bestetik, gaixotasun infekzioso bat denez, biztanleei zuzendu beharreko gomendio- eta prebentzio-neurriak zehaztu nahi izan ditugu, horretarako gomendio-neurriak modu argi batean adieraziz.

Beraz, egindako errebisioaren emaitzak islatzeaz gain, etorkizuneko erronkatzat hartzen ditugun helburu eta gomendioak ere azalduko dizkizuegu.

\section{Material eta metodoak}

Listeriosiaren prozesu diagnostiko eta terapeutikoa zehazteko bilaketa bibliografikoa egin da.

Atzera begirako behaketa deskribatzailearen bidez, Gipuzkoan baieztatu diren listeriosi kasuen ezaugarri kliniko eta epidemiologikoak zehaztu dira.

Kasuen erregistrorako, Espainiako Epidemiologia Zentroko protokoloen kasu-definizioa erabili da eta kasu bakoitzari galdeketa epidemiologiko, mikrobiologiko eta ingurugirokoak egin zaizkio. Ingurumen Ikerkuntza eta Osasun Publikoko teknikariek egin dute eta laginen azterketa Osasun Publikoko laborategiak egin du. Laginen azterketa molekularra PFGE (pulsed-field gel electrophoresis) teknikaren bidez egin da, modu horretan andui ezberdinak isolatuz. Ikerketa molekularrak Donostia Ospitaleko Mikrobiologia Zerbitzuan eta Euskal Autonomia Erkidegoko Mikrobiologia Zentroan egin dira.

Donostia Ospitaleko Epidemiologia Zerbitzuak emandako datuei esker, gure autonomia-erkidegoan izandako kasuen kontaketa bat egin da; eta, zehazki, Gipuzkoan izandako azken urteotako listeriosi kasuen bilaketa klinikoa eginez, zehaztu ahal izan da zein izan den haurdun eta jaioberrien kasuen ezaugarri eta bilakaera.

\section{Emaitzak}

2013an, 10 autonomia-erkidegok 120 listeriosi kasu berriri buruzko datuak eskaini zituzten. Euskal Autonomia Erkidegoa (EAE) da, ordea, kasuen gorakada esanguratsua atzeman duen bakarra. 2013an, EAEn, 74 kasu jakinarazi ziren, azken hamar urteetako kopuruaren hirukoitza. 
2013ko otsailetik 2014ko otsailera, Listera monocytogenesaren 31 kasu berri jakinarazi dira Gipuzkoako Mikrobiologia Zerbitzuan; eta 2012. urtean 11 kasu baino ez ziren jakinarazi. 2008 eta 2012 urteen bitartean jakinarazitako kasuen batezbestekoa 9 kasu/urte izan da (1. taula).

1. taula. Listeria kasuen intzidentzia. Gipuzkoan adierazitako Listeria monocytogenes kasuen intzidentzia-tasa 2008-2014 urteen bitartean.

\begin{tabular}{|c|c|c|c|c|c|c|c|}
\hline häĞ] & +60 & $16 \sigma \in[$ & 1660 & 1600 & †бб㕲 & 1606 & 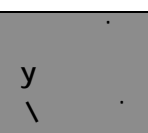 \\
\hline$\angle A Z A M$ & 3 & 9 & 8 & 11 & 11 & 22 & 9 \\
\hline dăEĂŬ & $0,42 \times 10^{5}$ & $1,27 \times 10^{5}$ & $1,13 \times 10^{5}$ & $1,56 \times 10^{5}$ & $1,56 \times 10^{5}$ & $3,12 \times 10^{5}$ & \\
\hline 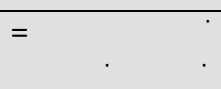 & -- & -- & 1 & 1 & 4 & 7 & 3 \\
\hline 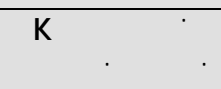 & -- & -- & -- & 2 & 4 & 4 & 1 \\
\hline
\end{tabular}

1. irudia. Gipuzkoako Mikrobiologia Zerbitzuari adierazitako Listeria monocytogenes kasuen eboluzioa.

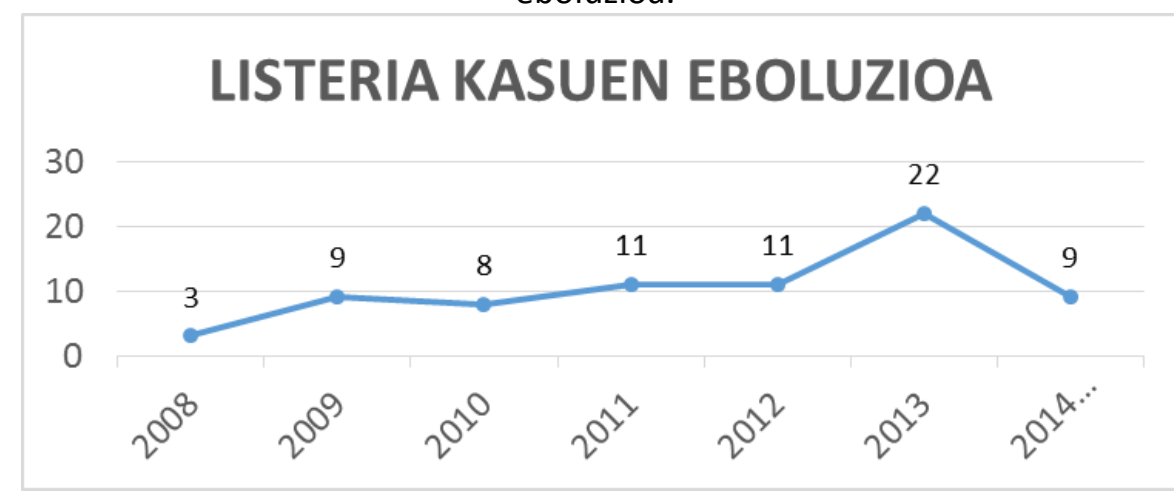

Elektroforesi bidez egindako behaketa molekularrak andui ezberdinen taldekatze konkretuak zeudela adierazi zuen. Taldekatzeetako bati 14 kasu zegozkion eta la patroikoa zen. Beste taldekatzeak 21 kasu biltzen zituen, eta I patroikoa zen. Azken taldekatze horren azterketaren ostean, arriskuko elikagaia foie zela ohartu ziren (OR=18 IC 95\%, 3.4-95.2 p=0.0001).

2012ko otsailetik eta 2014ko otsaila bitartean 42 kasu jakinarazi dira; 23 (\%55) haurdunaldiarekin lotuta, 14 emakume haurdun eta 9 jaioberri. 14 haurdun horietatik 8 hiru taldekatzetan bildu dira eta gainontzekoak kasu esporadikoak izan dira (1. eta 2. irudiak). 
Jatorrizko artikulua

2. irudia. Arrisku-taldeen araberako listeria kasuen banaketa Gipuzkoan.

\section{ARRISKU-TALDEEN ARABERAKO LISTERIA KASUEN BANAKETA}

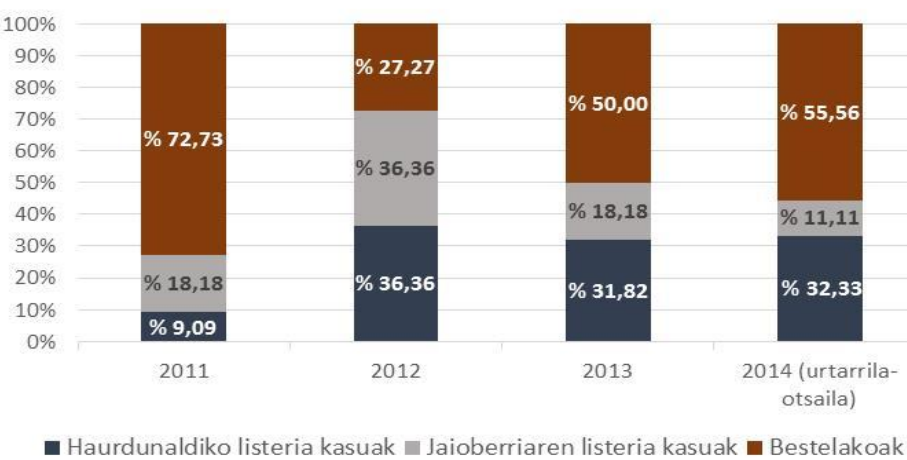

Jarraian 3 taldekatzeak deskribatzen dira (2. eta 3. taulak).

2. taula. Jaioberrien eta haurdunaldiko listeria kasuen ezaugarri epidemiologikoak Gipuzkoan (2012/14)

\begin{tabular}{|c|c|c|c|c|c|c|c|c|}
\hline & KASUA & ADINA & HERRIA & $\begin{array}{l}\text { SINTOMEN } \\
\text { HASIERA- } \\
\text { DATA }\end{array}$ & SAILKAPENA & $\begin{array}{l}\text { ARRISKUKO } \\
\text { ELIKAGAIA }\end{array}$ & PFGE & TALDEKATZEA \\
\hline \multirow{8}{*}{2012} & 1 & 34 & DONOSTIA & $2012 / 05 / 10$ & $\begin{array}{l}\text { HAURDUNALDIKO } \\
\text { LISTERIOSIA }\end{array}$ & $\begin{array}{c}\text { GAZTA } \\
\text { BIGUNAK }\end{array}$ & Ezezaguna & $\begin{array}{c}\text { Kasu } \\
\text { esporadikoa }\end{array}$ \\
\hline & 2 & Jaioberria & & & $\begin{array}{l}\text { JAIOBERRIAREN } \\
\text { LISTERIOSIA }\end{array}$ & & & $\begin{array}{c}\text { Kasu } \\
\text { esporadikoa }\end{array}$ \\
\hline & 3 & 32 & LASARTE & $2012 / 05 / 23$ & $\begin{array}{l}\text { HAURDUNALDIKO } \\
\text { LISTERIOSIA }\end{array}$ & FOIE GRASA & Ezezaguna & $\begin{array}{c}\text { Kasu } \\
\text { esporadikoa }\end{array}$ \\
\hline & 4 & Jaioberria & & & $\begin{array}{c}\text { JAIOBERRIAREN } \\
\text { LISTERIOSIA }\end{array}$ & & & $\begin{array}{c}\text { Kasu } \\
\text { esporadikoa }\end{array}$ \\
\hline & 5 & 41 & TOLOSA & $2012 / 11 / 16$ & $\begin{array}{l}\text { HAURDUNALDIKO } \\
\text { LISTERIOSIA }\end{array}$ & $\begin{array}{l}\text { GAZTA ETA } \\
\text { MOUSSEA }\end{array}$ & Laginik eza & 1. taldekatzea \\
\hline & 6 & Jaioberria & TOLOSA & & $\begin{array}{c}\text { JAIOBERRIAREN } \\
\text { LISTERIOSIA }\end{array}$ & & $\begin{array}{l}\text { Loturadun } \\
\text { anduia }\end{array}$ & 1. taldekatzea \\
\hline & 7 & 29 & TOLOSA & $2012 / 12 / 11$ & $\begin{array}{l}\text { HAURDUNALDIKO } \\
\text { LISTERIOSIA }\end{array}$ & GAZTAK & $\begin{array}{c}\text { Loturadun } \\
\text { anduia }\end{array}$ & 1. taldekatzea \\
\hline & 8 & Jaioberria & TOLOSA & & $\begin{array}{l}\text { JAIOBERRIAREN } \\
\text { LISTERIOSIA }\end{array}$ & & $\begin{array}{l}\text { Loturadun } \\
\text { anduia }\end{array}$ & 1. taldekatzea \\
\hline \multirow{11}{*}{2013} & 1 & 22 & ZALDIBIA & $2013 / 01 / 27$ & $\begin{array}{l}\text { HAURDUNALDIKO } \\
\text { LISTERIOSIA }\end{array}$ & Ezezaguna & $\begin{array}{l}\text { Erlazio } \\
\text { gabeko } \\
\text { anduia } \\
\end{array}$ & $\begin{array}{c}\text { Kasu } \\
\text { esporadikoa }\end{array}$ \\
\hline & 2 & 31 & EIBAR & $20113 / 08 / 02$ & $\begin{array}{l}\text { HAURDUNALDIKO } \\
\text { LISTERIOSIA }\end{array}$ & $\begin{array}{r}\text { MOZTUTAKO } \\
\text { HESTEBETEA }\end{array}$ & la patroia & 2. taldekatzea \\
\hline & 3 & 37 & ERMUA & $2013 / 08 / 31$ & $\begin{array}{l}\text { HAURDUNALDIKO } \\
\text { LISTERIOSIA }\end{array}$ & $\begin{array}{l}\text { MOZTUTAKO } \\
\text { HESTEBETEA }\end{array}$ & $\begin{array}{l}\text { Erlazio } \\
\text { gabeko } \\
\text { anduia }\end{array}$ & $\begin{array}{c}\text { Kasu } \\
\text { esporadikoa }\end{array}$ \\
\hline & 4 & 34 & AZPEITIA & $2013 / 09 / 13$ & $\begin{array}{c}\text { HAURDUNALDIKO } \\
\text { LISTERIOSIA }\end{array}$ & $\begin{array}{l}\text { MOZTUTAKO } \\
\text { HESTEBETEA }\end{array}$ & la anduia & 2. taldekatzea \\
\hline & 5 & Jaioberria & AZPEITIA & & $\begin{array}{c}\text { JAIOBERRIAREN } \\
\text { LISTERIOSIA }\end{array}$ & & la anduia & 2. taldekatzea \\
\hline & 6 & 39 & ELGOIBAR & $2013 / 09 / 24$ & $\begin{array}{c}\text { HAURDUNALDIKO } \\
\text { LISTERIOSIA }\end{array}$ & Ezezaguna & Laginik eza & 2. taldekatzea \\
\hline & 7 & Jaioberria & ELGOIBAR & & $\begin{array}{l}\text { JAIOBERRIAREN } \\
\text { LISTERIOSIA }\end{array}$ & & la anduia & 2. taldekatzea \\
\hline & 8 & Jaioberria & ELGOIBAR & & $\begin{array}{l}\text { JAIOBERRIAREN } \\
\text { LISTERIOSIA }\end{array}$ & & la anduia & 2. taldekatzea \\
\hline & 9 & 30 & ANDOAIN & $2013 / 11 / 17$ & $\begin{array}{l}\text { HAURDUNALDIKO } \\
\text { LISTERIOSIA }\end{array}$ & $\begin{array}{c}\text { PATE ETA } \\
\text { HESTEBETEA }\end{array}$ & $\begin{array}{l}\text { Erlazio } \\
\text { gabeko } \\
\text { anduia }\end{array}$ & $\begin{array}{c}\text { Kasu } \\
\text { esporadikoa }\end{array}$ \\
\hline & 10 & 33 & ELGETA & $2013 / 11 / 10$ & $\begin{array}{l}\text { HAURDUNALDIKO } \\
\text { LISTERIOSIA }\end{array}$ & Ezezaguna & I anduia & 3. taldekatzea \\
\hline & 11 & Jaioberria & & & $\begin{array}{l}\text { JAIOBERRIAREN } \\
\text { I ISTFRIOSIA }\end{array}$ & & & $\begin{array}{c}\text { Kasu } \\
\text { esnnradikna }\end{array}$ \\
\hline
\end{tabular}

Olazabal, Marin eta Lekuona 


\begin{tabular}{|c|c|c|c|c|c|c|c|c|}
\hline & KASUA & ADINA & HERRIA & $\begin{array}{c}\text { SINTOMEN } \\
\text { HASIERA- } \\
\text { DATA }\end{array}$ & SAILKAPENA & $\begin{array}{c}\text { ARRISKUKO } \\
\text { ELIKAGAIA }\end{array}$ & $\begin{array}{c}\text { PFGE } \\
\text { TALDEKATZEA }\end{array}$ \\
\cline { 2 - 8 } & 1 & 33 & ASTIGARRAGA & $2014 / 01 / 03$ & $\begin{array}{c}\text { HAURDUNALDIKO } \\
\text { LISTERIOSIA }\end{array}$ & MOUSSEA & I anduia & 3. taldekatzea \\
\cline { 2 - 8 } & 2014 & 28 & DONOSTIA & $2014 / 02 / 08$ & $\begin{array}{c}\text { HAURDUNALDIKO } \\
\text { LISTERIOSIA }\end{array}$ & FOIEA I patroia & 3. taldekatzea \\
\cline { 2 - 8 } & 3 & 38 & BERGARA & $2014 / 02 / 21$ & $\begin{array}{c}\text { HAURDUNALDIKO } \\
\text { LISTERIOSIA }\end{array}$ & MI CUITA I patroia & 3. taldekatzea \\
\cline { 2 - 8 } & 4 & Jaioberria & BERGARA & $2014 / 02 / 21$ & $\begin{array}{c}\text { JAIOBERRIAREN } \\
\text { I patroia }\end{array}$ & 3. taldekatzea \\
\hline
\end{tabular}

3. taula. Ezaugarri kliniko eta pronostikoak Gipuzkoako listeriosi kasuen artean, 2012-2014 urteetan

\begin{tabular}{|c|c|c|c|c|c|c|c|}
\hline & $\begin{array}{l}\text { Ka- } \\
\text { su- } \\
\text { ak }\end{array}$ & $\begin{array}{l}\text { Kontsultare } \\
\mathrm{n} \text { arrazoia }\end{array}$ & $\begin{array}{c}\text { Sintoma } \\
\text { nagusia }\end{array}$ & \begin{tabular}{|c|} 
Haurdu- \\
naldiko \\
astea \\
diagnostik \\
oaren \\
momen- \\
tuan \\
\end{tabular} & $\begin{array}{l}\text { Jasotako } \\
\text { tratamendua }\end{array}$ & Eboluzioa & $\begin{array}{l}\text { Erditze- } \\
\text { bidea }\end{array}$ \\
\hline \multirow{8}{*}{2012} & 1 & $\begin{array}{c}33+3 \text { aste, } \\
\text { H2A1. } \\
\text { Sukarra + } \\
\text { EGA }\end{array}$ & $\begin{array}{c}\text { Sukarra + } \\
\text { umetokiko } \\
\text { uzkurdurak } \\
\text { KTG: } \\
\text { fetuaren } \\
\text { takikardia + } \\
\text { uzkurdura } \\
\text { irregularrak }\end{array}$ & $33+3$ aste & $\begin{array}{c}\text { Biriken heltze- } \\
\text { prozesua: } \\
\text { Kortikoideak } \\
\text { (Betametasona) } \\
\text { ATB: } \\
\text { Amoxizilina/Klab } \\
\text { ulaniko, } \\
\text { Penizilina }\end{array}$ & $\begin{array}{c}\text { KTG: haurraren } \\
\text { ongizatea galtzeko } \\
\text { arriskua, urgentziazko } \\
\text { zesarea }\end{array}$ & Zesarea \\
\hline & 2 & $\begin{array}{c}\text { Goiztiartasu } \\
\text { na } 33+3 \text { aste }\end{array}$ & $\begin{array}{l}\text { Jaioberri } \\
\text { goiztiarra }\end{array}$ & & $\begin{array}{c}\text { Gentamizina + } \\
\text { Anpizilina }\end{array}$ & Eboluzio egokia & \\
\hline & 3 & Sukarra & Bakteriemia & 30 aste & $\begin{array}{l}\text { Biriken heltze- } \\
\text { prozesua, } \\
\text { jaiotzeko ondoko } \\
\text { antibiotikoak }\end{array}$ & & $\begin{array}{l}\text { Bagina } \\
\text { bidezko } \\
\text { erditzea }\end{array}$ \\
\hline & 4 & & $\begin{array}{l}\text { Jaioberri } \\
\text { goiztiarra }\end{array}$ & & & & \\
\hline & 5 & $\begin{array}{c}\text { H4E3 } \\
\text { Haurraren } \\
\text { mugimendu } \\
\text { en gutxitzea }\end{array}$ & $\begin{array}{c}\text { KTG: } \\
\text { haurraren } \\
\text { takikardia }\end{array}$ & $32+6$ aste & $\begin{array}{c}\text { Ospitaleratua } \\
\text { behaketa- } \\
\text { prozesuan. } \\
\text { Kortikoideak } \\
\text { biriken heltze- } \\
\text { prozesurako. } \\
\text { Kultibo + Listeria: } \\
\text { erditze ostean, } \\
\text { Amoxizilina/Klab } \\
\text { ulaniko } 8758 \\
\text { orduz } 14 \text { egun } \\
\end{array}$ & & $\begin{array}{l}\text { 33. astean, } \\
\text { bagina } \\
\text { bidezko } \\
\text { erditzea }\end{array}$ \\
\hline & 6 & & $\begin{array}{l}\text { Jaioberri } \\
\text { goiztiarra }\end{array}$ & & & & \\
\hline & 7 & $\begin{array}{c}\mathrm{H} 2 \mathrm{E} 1 \\
\text { Metrorragia }\end{array}$ & $\begin{array}{c}\text { Metrorragia } \\
\text { umetokiko } \\
\text { uzkurdurak. } \\
\text { Sukarra. }\end{array}$ & $35+2$ aste & $\begin{array}{c}\text { Anpizilina+Genta } \\
\text { mizina jaiotze } \\
\text { ostean, kultibo } \\
\text { positiboa } \\
\text { plazenta eta ur- } \\
\text { poltsaren } \\
\text { mintzetan } \\
\text { listeriarentzat } \\
\end{array}$ & $\begin{array}{l}\text { Hilekoa baino odoltze } \\
\text { handiagoa, umetokiko } \\
\text { uzkurdurak eta } \\
\text { sukarra } \\
\text { Urgentziazko zesarea }\end{array}$ & Zesarea \\
\hline & 8 & & $\begin{array}{c}\text { Jaioberri } \\
\text { goiztiarra. } \\
\text { Pisua: } 2040 \\
\text { g } \\
\text { Apgarra: } 5 / 7\end{array}$ & & $\begin{array}{c}\text { Anpizilina+Genta } \\
\text { mizina }\end{array}$ & $\begin{array}{l}\text { Sepsi goiztiarra. } \\
\text { Listeriagatiko } \\
\text { bakteriemia } \\
\text { Meningitis susmoa, } \\
\text { garun-bentrikuluen } \\
\text { asimetriarekin }\end{array}$ & \\
\hline
\end{tabular}




\begin{tabular}{|c|c|c|c|c|c|c|c|}
\hline & $\begin{array}{l}\text { Ka- } \\
\text { su- } \\
\text { ak }\end{array}$ & $\begin{array}{l}\text { Kontsulta } \\
\text { ren } \\
\text { arrazoia }\end{array}$ & $\begin{array}{l}\text { Sintoma } \\
\text { nagusia }\end{array}$ & \begin{tabular}{|c} 
Haurdu- \\
naldiko \\
astea \\
diagnos \\
tikoaren \\
momen- \\
tuan \\
\end{tabular} & $\begin{array}{c}\text { Jasotako } \\
\text { tratamendua }\end{array}$ & Eboluzioa & $\begin{array}{l}\text { Erditze- } \\
\text { bidea }\end{array}$ \\
\hline \multirow{8}{*}{2013} & 1 & & & & & & \\
\hline & 2 & $\begin{array}{c}\text { H1E0 } \\
\text { Sukarra + } \\
\text { beherako } \\
\text { a }\end{array}$ & $\begin{array}{l}39.4 \text { ㅇ } \\
\text { Sukarra, } \\
\text { beherakoa } \\
\text { KTG: } \\
\text { haurraren } \\
\text { takikardia } \\
\text { eta } \\
\text { umetokiko } \\
\text { uzkurdurak }\end{array}$ & $\begin{array}{l}28+5 \\
\text { aste }\end{array}$ & $\begin{array}{l}\text { Anpizilina }+ \\
\text { Gentamizina } 14 \\
\text { egunez zain } \\
\text { barnetik }\end{array}$ & $\begin{array}{l}\text { Eboluzio egokia. } \\
\text { Ekografia: garun- } \\
\text { bentrikuluen } \\
\text { dilatazio xumea. } \\
\text { 35+4 astean, partoz } \\
\text { dator }\end{array}$ & $\begin{array}{c}\text { Bagina } \\
\text { bidezko } \\
\text { erditzea } \\
2470 \mathrm{~g} \\
\text { Apgarra } \\
9 / 9 . \\
\text { Jaioberri } \\
\text { osasuntsu } \\
\text { a }\end{array}$ \\
\hline & 3 & $\begin{array}{l}\text { H1E0 } \\
\text { Sukarra }\end{array}$ & $\begin{array}{l}\text { Sukarra eta } \\
\text { ondoez } \\
\text { orokorra }\end{array}$ & $\begin{array}{l}39+5 \\
\text { aste }\end{array}$ & $\begin{array}{l}\text { Amoxizilina/klab } \\
\text { ulaniko zain } \\
\text { barnetik } 8 \\
\text { orduro }\end{array}$ & $\begin{array}{l}\text { ATB zain bidez, eta } \\
\text { partoaren indukzioa } \\
\text { KTG: haurraren } \\
\text { takikardia + } \\
\text { dezelerazio atipikoak } \\
\text { Haurraren ongizatea } \\
\text { galtzeko arriskua } \\
\text { dela-eta, } \\
\text { urgentziazko zesarea } \\
\text { agintzen da } \\
\end{array}$ & $\begin{array}{c}\text { Zesarea } \\
\text { Jaioberria } \\
: 3210 \\
\text { Apgarra } \\
4 / 9\end{array}$ \\
\hline & 4 & $\begin{array}{c}\text { H2E1 } \\
\text { MAHG + } \\
\text { EGA }\end{array}$ & $\begin{array}{c}\text { Mintz } \\
\text { amniotikoe } \\
\mathrm{n} \text { haustura } \\
\text { eta } \\
\text { umetokiko } \\
\text { uzkurdurak }\end{array}$ & $\begin{array}{l}29+1 \\
\text { aste }\end{array}$ & $\begin{array}{c}\text { Amoxizilina/klab } \\
\text { ulaniko } \\
\text { Haurraren } \\
\text { babes } \\
\text { neurologikoa: } \\
\text { Sulfato Mg } \\
\end{array}$ & $\begin{array}{l}\text { Erditze-prozesua } \\
\text { geratzeko } \\
\text { ezintasuna; erditze } \\
\text { goiztiarra } 29+1\end{array}$ & $\begin{array}{l}\text { Bagina } \\
\text { bidezko } \\
\text { erditzea }\end{array}$ \\
\hline & 5 & & $\begin{array}{c}1495 \mathrm{~g} \\
\text { Apgarra } \\
6 / 8\end{array}$ & & Anpizilina & \begin{tabular}{|c|} 
Mintz hialinoen \\
gaixotasuna \\
Jaioberriaren \\
listeriosia Ikterizia \\
\end{tabular} & \\
\hline & 6 & $\begin{array}{c}\text { H2E1 } \\
\text { Bikiak + } \\
\text { EGA }\end{array}$ & $\begin{array}{c}\text { Kontrakzio } \\
\text { ak }\end{array}$ & 34 aste & & $\begin{array}{l}\text { Lehenengo bikia } \\
\text { ipurdiz datorrela-eta, } \\
\text { urgentziazko zesarea }\end{array}$ & Zesarea \\
\hline & 7 & $\begin{array}{c}\text { Pisua } \\
2010 \\
\text { Apgarra: } \\
8 / 10\end{array}$ & $\begin{array}{l}\text { Listeria + } \\
\text { Goiztiartas } \\
\quad \text { una }\end{array}$ & & & & \\
\hline & 8 & $\begin{array}{c}\text { Pisua } \\
2000 \\
\text { Apgarra } \\
10 / 10 \\
\end{array}$ & $\begin{array}{l}\text { Listeria + } \\
\text { Goiztiartas } \\
\quad \text { una }\end{array}$ & & & & \\
\hline
\end{tabular}




\begin{tabular}{|c|c|c|c|c|c|c|c|}
\hline & $\begin{array}{l}\text { Ka- } \\
\text { su- } \\
\text { ak }\end{array}$ & $\begin{array}{l}\text { Kontsultar } \\
\text { en arrazoia }\end{array}$ & $\begin{array}{l}\text { Sintoma } \\
\text { nagusia }\end{array}$ & $\begin{array}{c}\text { Haurdu- } \\
\text { naldiko } \\
\text { astea } \\
\text { diagnos } \\
\text { tikoaren } \\
\text { momen- } \\
\text { tuan }\end{array}$ & $\begin{array}{l}\text { Jasotako } \\
\text { tratamendua }\end{array}$ & Eboluzioa & $\begin{array}{l}\text { Erditze- } \\
\text { bidea }\end{array}$ \\
\hline & 9 & $\begin{array}{c}\text { H1E0, } \\
\text { bikiak } \\
\text { Sukarra, } \\
\text { goitikak, } \\
\text { artikulazioe } \\
\text { tako mina, } \\
\text { min } \\
\text { muskularra } \\
\text {, buruko } \\
\text { mina }\end{array}$ & $\begin{array}{c}\text { Sukarra, } \\
\text { ondoez } \\
\text { orokorra } \\
\text { Ekografia: } \\
\text { bikietako } \\
\text { baten } \\
\text { umetoki } \\
\text { barneko } \\
\text { heriotza }\end{array}$ & $\begin{array}{l}29+6 \\
\text { aste }\end{array}$ & $\begin{array}{c}\text { Ospitaleratu: } \\
\text { Betametasona } \\
\text { Antibiotikoak zain } \\
\text { barnetik }\end{array}$ & $\begin{array}{l}\text { Ospitaleratzean, } \\
12 \text { ordura, } \\
\text { haurraren } \\
\text { bradikardia } \\
\text { dela-eta, } \\
\text { urgentziazko } \\
\text { zesarea. } \\
\text { Zesarea ostean: } \\
\text { umetokiko } \\
\text { arterien } \\
\text { enbolizazioa } \\
\text { uzkurdura- } \\
\text { ezintasuna dela- } \\
\text { eta. } \\
\text { - Shock } \\
\text { hipobolemikoa }\end{array}$ & Zesarea \\
\hline & 10 & $\begin{array}{c}\text { Jaioberri } \\
\text { goiztiarra } \\
30 \text { aste }\end{array}$ & $\begin{array}{c}\text { Goiztiartasun } \\
\text { a }+ \\
\text { Jaioberriaren } \\
\text { listeriosia }\end{array}$ & & & & \\
\hline & 11 & & $\begin{array}{l}\text { JAIOBERRI } \\
\text { HILA }\end{array}$ & $\begin{array}{l}\text { Umetoki } \\
\text { barneko } \\
\text { haurrar } \\
\text { en } \\
\text { heriotza }\end{array}$ & & & \\
\hline \multirow{4}{*}{2014} & 1 & $\begin{array}{c}\text { H1E0 } \\
\text { Uzkurdurak }\end{array}$ & $\begin{array}{l}\text { Umetokiko } \\
\text { uzkurdurak }\end{array}$ & $\begin{array}{l}40+6 \\
\text { aste }\end{array}$ & $\begin{array}{c}\text { Amoxizilina/klabula } \\
\text { niko zain barnetik . } \\
\text { Erditze } \\
\text { ondorenean: } \\
\text { Anpizilina }\end{array}$ & $\begin{array}{c}\text { KTG: } \\
\text { dezelerazioak } \\
\text { direla-eta, } \\
\text { erditzearen } \\
\text { indukzioa } \\
\end{array}$ & $\begin{array}{l}\text { Bagina } \\
\text { bidezko } \\
\text { erditzea }\end{array}$ \\
\hline & 2 & $\begin{array}{c}\text { Hilekoa } \\
\text { baino } \\
\text { odoltze } \\
\text { handiagoa }\end{array}$ & Metrorragia & $\begin{array}{l}13+1 \\
\text { aste }\end{array}$ & $\begin{array}{c}\text { Amoxizilina } 500 / 8 \\
\text { orduro } 7 \text { egun }\end{array}$ & $\begin{array}{l}\text { Osoa ez den } \\
\text { abortua }\end{array}$ & $\begin{array}{l}\text { Bagina } \\
\text { bidezko } \\
\text { erditzea }\end{array}$ \\
\hline & 3 & Sukarra & $\begin{array}{l}\text { Sukarra eta } \\
\text { digestio } \\
\text { aparatuko } \\
\text { sintomak }\end{array}$ & & $\begin{array}{c}\text { Antibiotiko bidezko } \\
\text { tratamendua }\end{array}$ & & $\begin{array}{l}\text { Bagina } \\
\text { bidezko } \\
\text { erditzea }\end{array}$ \\
\hline & 4 & $\begin{array}{l}\text { Jaioberriar } \\
\text { en sepsia }\end{array}$ & & & & & \\
\hline
\end{tabular}

HAE, H: Haurdunaldia, E: erditzea, A: abortua

EGA: erditze goiztiarraren arriskua

KTG: kardiotokografoa

ATB: antibiotikoa

MAHG: mintz amniotikoaren haustura goiztiarra

Lehenengo taldekatzea (antzeko patroi molekularra), 2012. urtea

2012ko azaroan eta abenduan, listeriosi-taldekatze bat agertu zen bi haurdun eta haien jaioberrien artean. 
Bi haurdunek sukar-agerraldi eta erditze goiztiarrak izan zituzten. Jaioberriek meningoenzefalitisa garatu eta, ondorioz, Donostia Ospitaleko Jaioberrien Unitatean ospitaleratuta egon beharra izan zuten. Bi emakumeak herri berekoak ziren, Tolosa, eta galdeketa epidemiologikoak ez zuen arriskuko elikagairik identifikatu. Elkarren artean antzeko zuten ezaugarri bakarra harategi bereko bezeroak izatea izan zen. Elektroforesi bidez eginiko azterketan taldekatzeko 3 lagin erlazionatuta zeudela ohartu ziren ( 2 jaioberri eta ama 1 ).

\section{Bigarren taldekatzea (la tipoa), 2013. urtea}

Talde honetan 7 kasu biltzen dira: haurdunaldiko 3 listeriosi, jaioberriaren kasu 1 eta beste 3 listeriosi mota.

2013. urteko kasu hauek, abuztuan eta irailean aurkeztu ziren. 3 haurdun biltzen zituen, Elgoibar, Azpeitia eta Eibarko bizilagun zirenak. 3 emakume horietatik bik erditze goiztiarrak izan zituzten.

Elikagaien inguruko galdeketan ez zen arriskuko janaririk identifikatu;hala ere, aipatzekoa da hiru haurdunek sukaldatu gabeko york urdaiazpikoa kontsumitu zutela.

Genotipoaren azterketa egin ostean, agerraldiaren baieztapena egin zen. Ingurugiroko azterketan elikagai ezberdinen azterketa egin zen (mota ezberdinetako york urdaiazpikoak), eta guztiek betetzen zuten arautegiak zehaztutako muga $<100 \mathrm{ufc/g}$ izan zen Listeria monocytogenesarentzat.

\section{Hirugarren taldekatzea (I tipoa). 2013-2014 urteak}

Taldekatze honek 11 kasu biltzen ditu: 4 haurdunaldiko, jaioberriaren kasu 1 eta bestelako 6 kasu.

Kasuak 2013ko abendutik 2014ko otsailera azaldu ziren. Galdeketan lortutako informazioaren arabera, ez zen arriskuko elikagaia identifikatu. Hala ere, kasu guztiek foiea kontsumitu zuten Eguberri jaietan (2013ko abenduaren 24tik, 2014ko urtarrilaren 1era). Ingurugiroko azterketan zenbait lagin jaso ziren, bai etxekoak bai establezimendu ezberdinetakoak, eta eginiko azterketan Listeria monocytogenesaren kontaketa altua identifikatu zuten $\left(5.2 \times 10^{4} \mathrm{ufc} / \mathrm{g}\right)$. Datu horiek agerraldia izan zela baieztatu zuten, eta foiea zehaztu zuten taldekatze honen eragile gisa.

\section{Etorkizuneko erronkak}

Listeria zelula barneko hazkuntza duen bazilo gram-positibo bat da; plazenta eta muga hematoentzefalikoa zeharkatzeko ahalmen handikoa. Immunitate baxuko egoeretan, hala nola haurdunaldian, infekzioa garatzeko arriskua areagotu egiten da (17-20 aldiz), batez ere hirugarren hiruhilekoan $(1,2)$. Mikroorganismo honek haurdun eta jaioberriengan eragiten dituen ondorio kaltegarrien ondorioz, haren garrantzia areagotu egin da azken agerraldietan.

\subsection{Infekzioaren jatorria}

Infekzio-iturria kutsatutako elikagaien bidezkoa da. Amaren infekzioaren ondorioz, eta odolean zehar zabaltzen den infekzioa dela-eta, bakterioa, plazenta zeharkatu eta fetua infektatzeko gai da $(2,4)$.

\subsection{Infekzioaren diagnostikoa:}

Haurdunaren infekzioa detektatzea zaila izan liteke, sintoma inespezifikoak eragiten ditu eta $(1,2,5)$ :

- Lehenengo eta bigarren hiruhilekoan: infekzio argirik gabeko sukarra ( $\left.>38^{\circ} \mathrm{C}\right)$ eta kasuen $\% 20 \mathrm{an}$ digestio-aparatuko sintomak

- Hirugarren hiruhilekoan: korioamnionitisa.

Baieztapen diagnostikoa lortzeko kultiboak baino ez ditugu; lagin horiek gorputzeko fluido edo ehun esteriletakoak izan litezke (odola, likido amniotikoa...) (1).

Parametro biokimiko sentikorrena PCRa da eta haren balio altuak atzematen dira kasu ia guztietan.

Ikus segi beharreko jarraibideak (2) sukarra duten haurdunengan (3. eta 4. irudiak). 
3. irudia. Sukarra duen haurdunaren jarraibide-eskema.

HAURDUNA $\geq 38^{\circ} \mathrm{C}+$ INFEKZIO-FOKU ARGIRIK GABEA

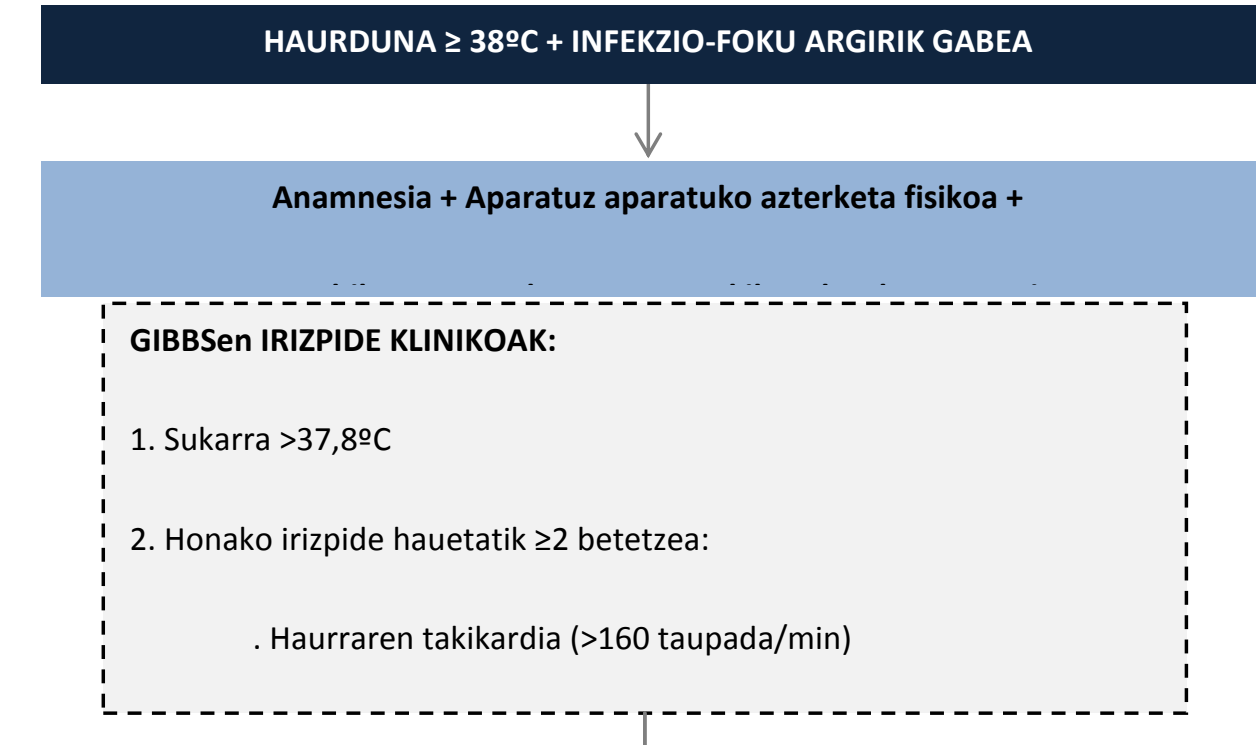

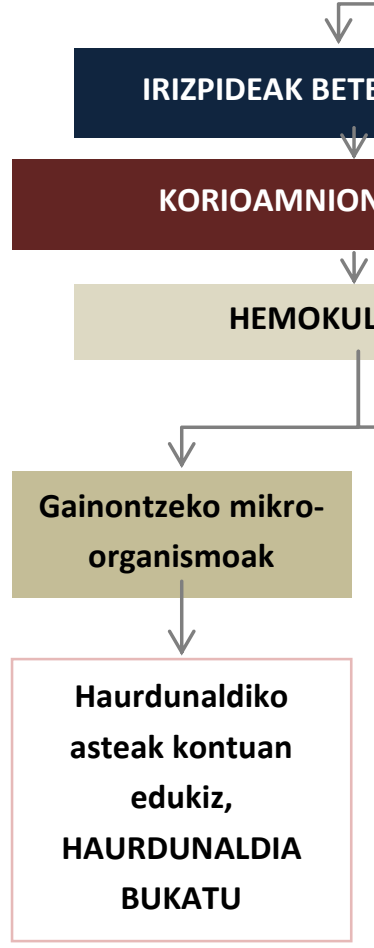

IRIZPIDEAK BETETZEN DITU

\section{KORIOAMNIONITIS KLINIKOA}

$\sqrt{2}$

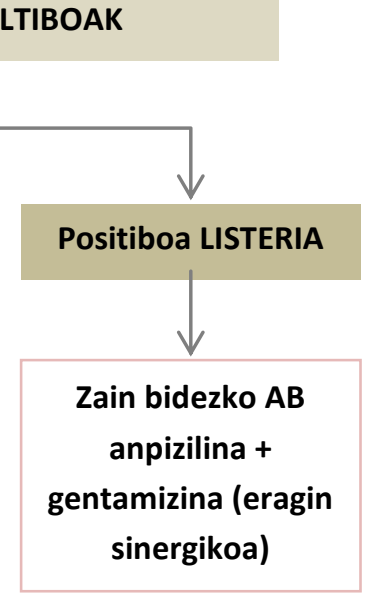


4. irudia. Sukarra eta digestio-aparatuko sintomak dituen haurdunaren jarraibide-eskema.

\section{HAURDUNA $\geq 38$ 으 + Digestio-aparatuko sintomak}
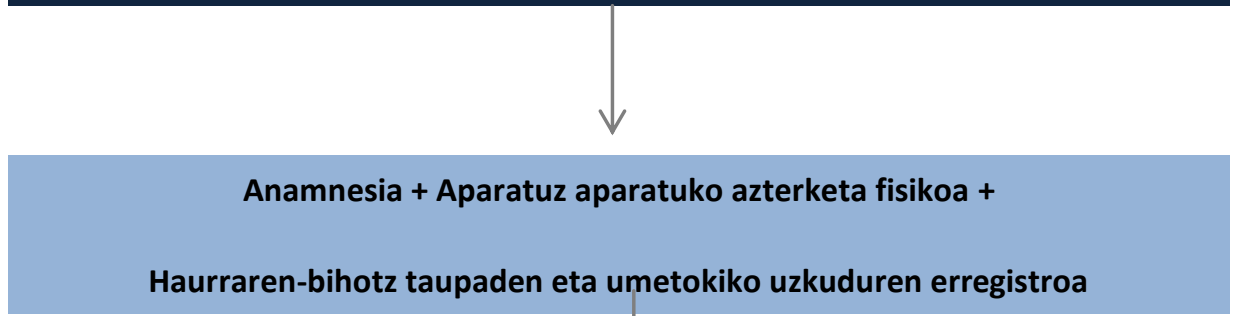

Haurraren-bihotz taupaden eta umetokiko uzkuduren erregistroa

LISTERIOSIA IZATEKO SUSMO ALTUA

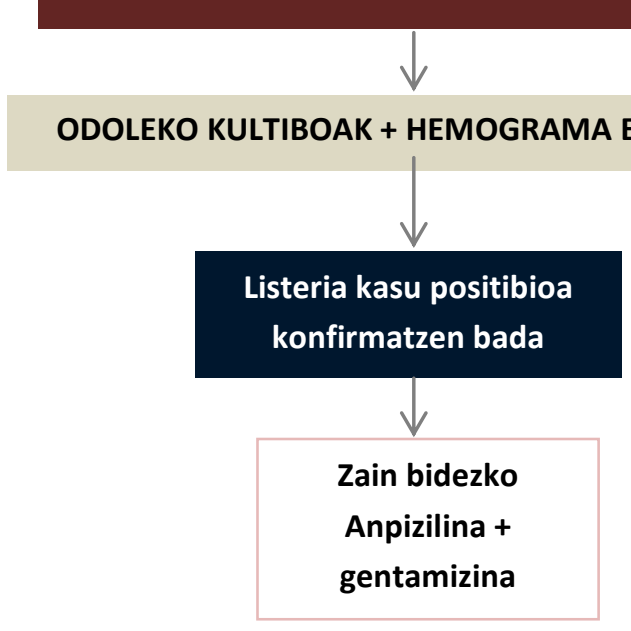

\subsection{Infekzioaren arriskuak}

Sistema immune egokidun haurdunengan listeriak sintomatologia ahul eta eskasa eragiten du. Hala eta guztiz ere, fetuari dagokionez ondorio larriak eragin ditzake.

Infekzioa garatutako unearen arabera, ondorioak ezberdinak izan daitezke $(2,5)$ :

- Infekzioa lehenengo edo bigarren hiruhilekoan garatzen bada (kasuen \% 20): fetuaren heriotza edo abortu septikoak.

- Hirugarren hiruhilekoan eskuratzen bada, ordea (kasuen \% 80): kasuen 2/3k korioamnionitisa eta erditze goiztiarrak eragiten ditu, jaiotza inguruko heriotza-arriskua \% 20koa delarik.

2012-2014 urte bitarteko Gipuzkoako listeriosi kasuen eboluzioa ondokoa izan da:

- 2012. urtea:

- Haurdunaldiko 4 kasu eta jaioberriaren beste 4 kasu adierazi ziren.

- Kasu guztietan, sintomak hirugarren hiruhilekoan aurkeztu ziren.

- Haurdunetatik hiruk sukarragatik kontsultatu zuten, eta batek fetuaren mugimenduen gutxitzeagatik.

- Kasu guztietan erditzea goiztiarra izan zen.

- 2013. urtea:

- Haurdunaldiko 7 kasu eta jaioberriaren 4 kasu.

- Kasu guztiak hirugarren hiruhilekoan aurkeztu ziren. Guztiak, bat izan ezik, jaiotze goiztiarrak izan ziren.

- 2014. urtea:

- Haurdunaldiko 3 kasu eta jaioberriaren kasu bat

- Kasuetako bat 13 asteko abortu berantiarra izan zen. 


\section{Eztabaida}

\subsection{Kasuen ezaugarriak}

Infekzioaren ezaugarriei dagokienez, gure inguruan kasu gehienak haurdunaldiaren lehengo hiruhilekoan gertatu dira. Literaturak dioenez, listeriosi kasu gehienak $1 / 2 a, 1 / 2 b$ eta $4 b$ anduiek eragindakoak izan dira. Gure inguruan ordea, 1 eta 1 a anduiak izan dira isolatu direnak.

Kasuen banaketa eta ezaugarriak ezberdinak izan dira urte batetik bestera. 2012ko kasuek banaketa topografiko zehatz bat izan zuten, herri edo inguru konkretu batean. 2014ko kasuak, ordea, elikagai konkretu bati loturikoak izan dira, Gipuzkoako herri ezberdinetan banatua izan zena.

\subsection{Jatorria zehaztearen ondorioak}

Lortutako datuen arabera, gure lurraldeko listeriosi kasuen igoeraren ondorioz prebentzio-neurriak areagotu behar direla atzeman dugu. Behaketa honen ostean, infekzio-bide nagusia elikagai kutsatuen bidezkoa dela ohartu gara.

Hori horrela izanda, gizarte-talde ahulenetan prebentzio neurriak areagotu behar dira eta segi beharreko jarraibideak helarazi behar zaizkie talde horiei.

\subsection{Zabaldu beharreko gomendioak}

Elikagaien inguruko heziketa egokia eta lehen mailako prebentzio-neurriak funtsezkoak dira beraz; eta gure kasuan haurdunei zuzenduko gatzaizkie batez ere.

Hainbat eta hainbat elikagairen bidez transmiti badaiteke ere, kasu gehienak honako hauekin erlazionatuta egon dira: barazki gordinak, esnekiak (gazta bigunak), haragi egosiak eta arrain ketuak.

\subsection{Listeria, umetoki barruan trata daitekeen koriomanionitisa?}

Gainontzeko korioamnionitis kasuekin alderatuz gero, zeinetan erditzearen indukzioa eta haurdunaldia amaitzea den ohiko ekinbidea, listeriosia, trata daitekeen eta erditzea muga egokian eta arazorik gabe eman litekeen egoera bat da. Diagnostiko goiztiar eta tratamendu antibiotiko egoki bati esker, listeriosiaren konplikazioak ekidin daitezke $(6,7)$.

Diagnostiko eta tratamendu egokiari esker ama zein jaioberriaren emaitzak behar bezalakoak dira. Arazoa, ordea, diagnostiko berantiar batek dakar; izan ere, prebenitu ordez konplikazioak tratatzen baitira kasu horietan. Lan honi esker ohartu gara 2012ko kasuen diagnostiko eta tratamendua erditu ondorengoa izan zela, behin plazenta eta mintzak aztertu ostean. Protokolo klinikoa ezarri ostean, ordea, diagnostikoa haurdunaldian zeharrekoa izan da eta ez erditu ostean. Hori dela-eta, aurrez aipatutako algoritmo edo protokoloa proposatzen dugu sintoma inespezifikoak dauzkaten haurdunen kasuetan $(6,7)$.

Lortutako datuen azterketa eta behaketa egin ostean, foku ezezaguneko sukarra duen haurdunaren kasuan bahetze-prozesuren bat egin behar ote den otu zaigu. Ondorioa, hau izan da: foku ezezaguneko sukarra duen haurdunean hemokultiboak egin behar direla listeriosi kasu posible bat deskartatzeko eta haien emaitzaren zain antibiotikoa ezarri.

Kasu ezberdinak kontuan izanik, kontsultaren arrazoia heterogeneoa dela ohartu gara, eta hein handi batean haurdunaldiko asteen araberakoa dela. Diagnostiko goiztiar eta tratamendu egokirako tresna azkarrena anamnesi egokia da. Anamnesia arrisku-faktore eta susmo klinikoan oinarritu behar da. 


\section{Ondorioak}

Lortutako datuen arabera, eta behaketa honen ostean infekzio-bide nagusia elikagai kutsatuen bidezkoa dela ohartuz, prebentzio-neurriak areagotu behar direla atzeman dugu eta horretarako elikagaien inguruko heziketa egokia eta lehen mailako prebentzio-neurriak azaltzen ditugu.

Bestalde, diagnostiko eta tratamendu goiztiarrak haurdunaldiaren eboluzioan duen garrantzia aipatzekoa da. Izan ere, diagnostiko eta tratamendu egoki batekin, infekzio horren konplikazioak ekidin daitezke $(6,7,8)$.

\section{Haurdunei zuzendutako gomendioak}

Listeriosia prebenitzeko jarraitu behar diren gomendioak haurdunaldiaren lehenengo hiruhilekoan ematen dira. Gaur egun, ahoz azaltzen dira eta informazio hori era egokian zabaltzeko, ondorengo azalpen-orria banatzea proposatzen dugu.

Hori guztia kontuan izanda, honako gomendio hauek aholkatzen dira $(1,4,9,10)$ :

- Elikagaiak ondo sukaldatu jan aurretik.

- Gordinik jan behar diren barazki eta frutak ondo garbitu.

- Elikagaiak hozkailuan tenperatura egokian mantendu, gordinik jan beharrekoak eta sukaldatuak banatuta.

- Ontzi eta gainazalekin elikagaiak kutsatzea saihestu. Eskuak eta gainazalak ondo garbitu gordinik jan beharreko elikagaiak erabili ostean.

- Jateko prest dauden elikagaiak eta hozkailuan denbora luzez egonikoak jatea saihestu. Ontzietan bildutako elikagaiak behin ireki ostean egunean bertan kontsumitu.

- Pasta biguneko gaztak jatea saihestu (Brie, Camembert, Roquefort...) bai eta arrantzako produktu ketuak ere.

- Hestebete (york urdaiazpikoa, mortadela...) sukaldatu gabeak jatea saihestu.

- Elikagaiak berriz berotzekotan, kantitate txikietan eta tenperatura altuetan sukaldatu. 
4. taula. Elikadura-gomendioak.

\begin{tabular}{|c|c|}
\hline SAIHESTU BEHARREKO ELIKAGAIAK & JAN LITEZKEEN ELIKAGAIAK \\
\hline $\begin{array}{l}\text { Frankurft erako saltxitxak, lata edo ontzietan } \\
\text { gordetako haragiak, jateko prest dauden haragi } \\
\text { aurrez prestatuak. }\end{array}$ & $\begin{array}{l}\text { Aurrez aipatutakoak, baldin ondo egosiak eta } \\
\text { tenperatura altuetan sukaldatuak izan badira. }\end{array}$ \\
\hline $\begin{array}{l}\text { Pasta biguneko gaztak: feta, brie, camembert, } \\
\text { gazta urdinak, gazta freskoa... } \\
\text { Edozein gazta pasteurizatu gabeko esnearekin } \\
\text { egina badago }\end{array}$ & $\begin{array}{l}\text { Esne pasteurizatuz eginiko gazta bigunak, } \\
\text { pasta gogorreko gaztak, mozzarela, igurzteko } \\
\text { prest dauden gaztak... }\end{array}$ \\
\hline $\begin{array}{l}\text { Latetan ez dauden edo esterilizatuak izan ez } \\
\text { diren pateak. }\end{array}$ & $\begin{array}{l}\text { Latetan kontserbatutako edo esterilizatutako } \\
\text { pateak. }\end{array}$ \\
\hline $\begin{array}{l}\text { Arrain ketuak: izokina, amuarraina, arrain zuriak, } \\
\text { bakailaoa, hegaluzea eta berdela. } \\
\text { Arrain edo itsaski gordinak. }\end{array}$ & $\begin{array}{l}\text { Arrain ketuak, baldin eta latan kontserbatuak eta } \\
\text { esterilizatuak izan badira. } \\
\text { Arraina eta izokina ondo sukaldatua izan bada, } \\
50 \text { ㄷ baino gehiagora. }\end{array}$ \\
\hline $\begin{array}{l}\text { Esne gordina edo esne mota horrekin } \\
\text { elaboratutako esnekiak. }\end{array}$ & $\begin{array}{l}\text { Esne pasteurizatua eta esne pasteurizatuz } \\
\text { eginiko esnekiak. }\end{array}$ \\
\hline Jateko prest dauden entsalada eta barazkiak. & $\begin{array}{l}\text { Etxean prestatutako entsaladak, baldin barazki } \\
\text { gordinak ondo garbituak izan badira. }\end{array}$ \\
\hline
\end{tabular}

- Elikagaiak ondo sukaldatu jan aurretik

- Gordinik jan behar diren barazki eta frutak ondo garbitu

- Elikagaiak hozkailuan tenperatura egokian mantendu, gordinik jan beharrekoak eta sukaldatuak banatuta.

- Ontzi eta gainazalekin elikagaiak kutsatzea saihestu. Eskuak eta gainazalak ondo garbitu, gordinik jan beharreko elikagaiak erabili ostean.

- Jateko prest dauden elikagaiak eta hozkailuan denbora luzez egonikoak jatea saihestu. Ontzietan bildutako elikagaik behin ireki ostean egunean bertan kontsumitu.

- Elikagaiak birberitzekotan, kantitate txikietan eta tenperatura altuetan kozinatu.

\section{HAURDUNALDIAN ZEHAR ELIKAGAI SEGURUAK INOIZ BAINO GEHIAGO.}

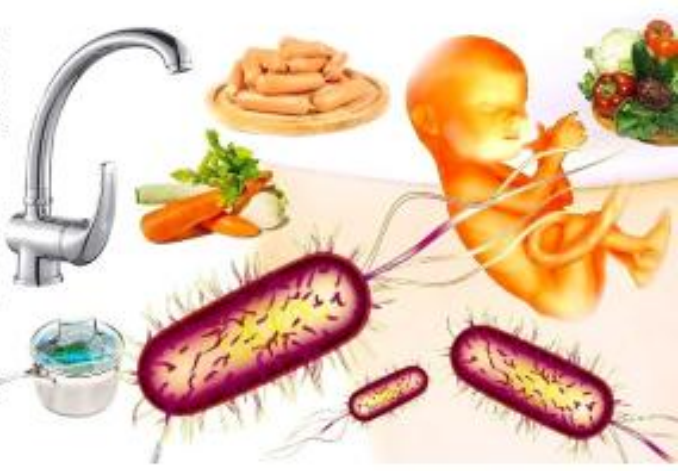

\section{Eskerrak eta oharrak}

Gure eskerrik beroenak Gipuzkoako Epidemiologia Zentroari, emandako laguntza eta datuengatik. 


\section{Erreferentzia bibliografikoak}

1. DynaMed Plus [Internet]. Ipswich (MA): EBSCO InformationServices. 1995 - . Record No. 905813, Listeriosisinpregnancy; [updated 2016 Jun 01, cited 2017-05-25]; Availablefrom http://www.dynamed.com/login.aspx?direct=true\&site=DynaMed\&id=905813.

2. Committee on ObstetricPractice, AmericanCollegeofObstetricians and Gynecologists. CommitteeOpinion No. 614: Managementofpregnantwomenwithpresumptiveexposure to Listeria monocytogenes. ObstetGynecol. 2014 Dec;124(6):1241-4.

3. Janakiraman V. Listeriosis in Pregnancy: Diagnosis, Treatment, and Prevention. Rev Obstet Gynecol. 2008;1(4):179-185.

4. Elinav H, Hershko-Klement A, Valinsky L, Jaffe J, Wiseman A, Shimon H, BraunE, Paitan Y, Block C, Sorek R, Nir-Paz R; Israeli Listeria StudyGroup..Pregnancy-associatedlisteriosis: clinicalcharacteristics and geospatialanalysisof a 10-yearperiodin Israel. ClinInfectDis. 2014 Oct;59(7):953-61.

5. Ricote $R$, Inmaculada $M$, MagdalenoDans $F$, Sancha Naranjo $M$, OmeñacaTeres $F$, GonzálezGonzález A. Corioamnionitishistológica y morbimortalidadneonatal: aproximación al síndrome de respuestainflamatoria fetal. RevChilObstetGinecol. 2010;75(3):172-8. Doi: 10.4067/S0717-75262010000300005

6. Aparicio Navarro B, Marcos Puig B, BalanzaChancosa R, Abad Carrascosa A, PellicerMartínez A. Listeriosis y embarazo. ¿Esrealmentetaninfrecuente? ProgObstetGinecol. 2008;51(4):23642. Doi: 10.1016/S0304-5013(08)71082-3

7. Montañez D, Camaño I, Villar O, GarcíaBurguillo A, Vallejo P. Listeriosisduranteelembarazo: importancia del tratamientoprecoz. ClinInvestGinecolObstet 2011;38(4):160-2. Doi: 10.1016/j.gine.2009.12.008

8. Edwards RK. Chorioamnionitis and labor. ObstetGynecolClinNorthAm. 2005;32(2):287-296, x.

9. Awofisayo A, Amar C, Ruggles R, Elson R, Adak GK, Mook P, Grant KA. Pregnancyassociatedlisteriosisin England and Wales. Epidemiollnfect. 2015;143(2):249-56.

10. Bondarianzadeh D, Yeatman H, Condon-Paoloni D. Listeria educationinpregnancy: lostopportunityforhealthprofessionals. Aust N Z J PublicHealth. 2007 Oct;31(5):468-74. Doi: 10.1111/j.1753-6405.2007.00120.x 